\title{
Assessing behavior and fate of micropollutants during wastewater treatment: Statistical analysis
}

\author{
Yahya EL HAMMOUDANI ${ }^{\dagger}$, Fouad DIMANE \\ Department of Energy and Environmental Civil Engineering, Applied Sciences Laboratory, Water and environment management Unit, National School \\ of Applied Sciences of Al-Hoceima, Abdelmalek Essaâdi University, Morocco
}

\begin{abstract}
This study examines the occurrence of micropollutants $(n=46)$ in raw sewage, as well as the fate of the removal performance for these substances by the Al-Hoceima city wastewater treatment plant. The treatment process removed more than $50-90 \%$ of heavy metals from the wastewater Polycyclic Aromatic Hydrocarbons and Polychlorinated Biphenyls were eliminated from wastewater by $20-50 \%$. The quality of the effluent discharged complied with national and international wastewater discharge standards. Statistical methods were applied to examine the relationships between the concentrations of micropollutants and macropollutants entering and leaving the wastewater treatment plant, and a model for estimating the production of micropollutants, based on a measurement of macro pollution parameters.
\end{abstract}

Keywords: Fate, Occurrence, Micropollutants, Urban wastewater, Sewage treatment plant, Statistical analysis

\section{Introduction}

Over the past few decades, the use of various chemical substances present in many of our daily lives has become a source of environmental pollution transported by urban wastewater [1]. Sewage treatment systems are the recipient of a wide variety of wastewaters to be treated [2]. They can come from different types of activities (domestic, industrial, craft, and hospital). These effluents contain various chemicals, some of which are described as micropollutants (MPs), such as polychlorinated biphenyls (PCBs), polycyclic aromatic hydrocarbons (PAHs) [3], and heavy metals (HMs) because they are present at low concentrations in the range of nanograms to micrograms per liter [4].

Micropollutants are inorganic and organic compounds resulting from human activity [5]. Most of these substances are endocrine disruptors and toxic to humans and the environment [5,6]. Reducing the input of micropollutants into the environment has become a major issue for the preservation of resources and public health [7]. Even if the mechanisms for eliminating conventional macropollution in wastewater treatment plants are understood and effective, this is not the case for most micropollutants [8]. In this context, operators have focused on the contamination of wastewater effluents by micropollutants and their behavior in wastewater treatment plants (WWTPs) [9].

Several studies have examined the removal of micropollutants in wastewater treatment plants using different types of biological treatments. They are considered one of the most promising technologies used for the treatment of urban wastewater [10]. Elimination of these compounds is not generally controlled by plant managers or authorities because there are few or no regulations regarding their discharge into water bodies. However, a scientific interest in this compounds appeared about ten years ago, as shown by the literature review of Pasquini et al. [11].

The PAHs are organic compounds that are widely distributed in the environment [12]. The main sources of pollution by PAHs are anthropogenic: road and river transport, combustion of fossil fuels (coal, fuel oil, and petroleum), incompleted combustion of organic products (oil-fired heating, forest fires, etc.) and certain industrial activities [13]. The PCBs comprise a class of more than 200 congeners. They are compounds formed from a biphenyl skeleton on which chlorine atoms are substituted in variable positions and numbers. Although all new uses have been banned since 1986, their use persists. As they are very persistent com-
This is an Open Access article distributed under the terms of the Creative Commons Attribution Non-Commercial License (http://creativecommons.org/licenses/by-nc/3.0/) which permits unrestricted non-commercial use, distribution, and reproduction in any medium, provided the original work is properly cited.

Copyright (C) 2021 Korean Society of Environmental Engineers
Received June 24, 2020 Accepted September 21, 2020

${ }^{\dagger}$ Corresponding author

Email: elhammoudani5@gmail.com

Tel: +212655624716 Fax: +212539981202

ORCID: 0000-0001-9356-9930 
pounds, they are still found in the environment in the residues of former industrial production (plasticizers, lubricants, dielectric fluids and, heat transfer fluids) [14]. The HMs are generally defined as naturally occurring metallic elements with a density greater than $5 \mathrm{~g} / \mathrm{km} 3$. They occur naturally in our environment and are used extensively in industry. Generally emitted in the form of very fine particles, they are carried by the wind and spread in soils and aquatic environments, contaminating flora and fauna and ending up in the food chain [15]. The target compounds were chosen according to their presence in domestic use, physicochemical properties to observe their possible partitioning between water and sludge in the wastewater treatment plant, and their socio-economic interest.

Within complex systems involving multiple variables, statistics can be an effective way to search for empirical links to reveal or describe behaviors, properties, or phenomena. Then we can look for a physical justification for the facts that we observe. As an example, a statistical approach was applied to identify a possible change in the wastewater treatment plant's behavior: a variation in the correlation coefficients or an inadequacy of the new measurements with the previous model could be a relevant way to identify certain problems [16]. Moreover, a statistical study has determined the main operating parameters relating to process performance in three paper mill treatment plants [17].

Located on the Mediterranean coast north of MOROCCO (Fig. 1), the city of Al-Hoceima has a population of 62,030 inhabitants [18]. The region has a semi-arid Mediterranean-type climate, characterized by hot, dry summers and cool, rainy winters. Its economy is based on fishing and tourism [19]. The Al-Hoceima wastewater treatment plant is located in the north-west of the city and covers an area of 4 ha (Fig. 1). It was commissioned in 1996, and to follow the evolution of urbanization and population, the plant was rehabilitated in 2011.

The aim of this paper, which presents the results obtained in this study, provides information on wastewater contamination in urban areas (presence rate, level of contamination, behavior

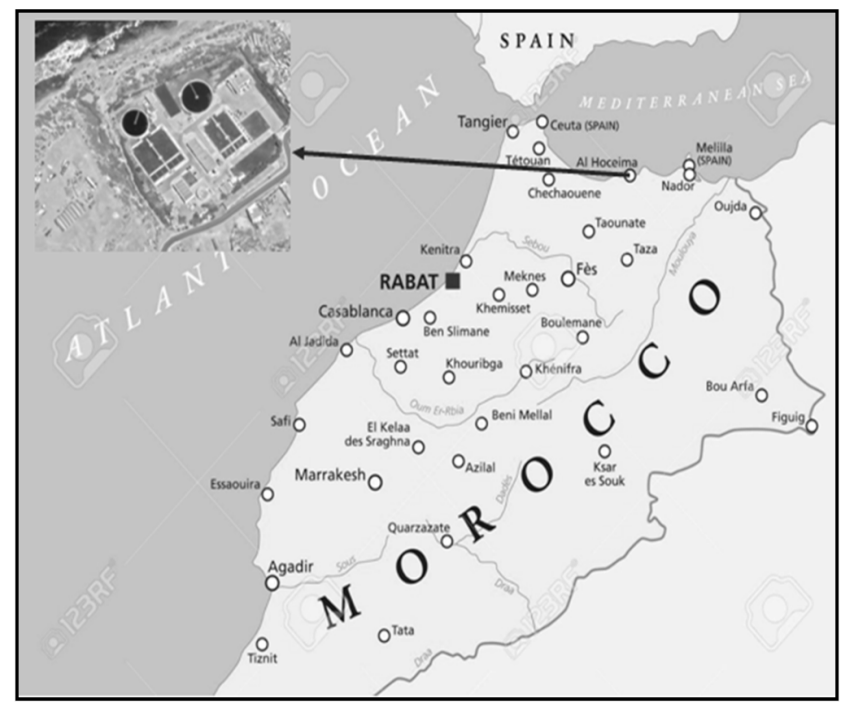

Fig. 1. Location of the WWTP of Al-Hoceima city. in the WWTP), evaluates the removal (biodegradation or adsorption on sludge) of these compounds from wastewater by biological treatment in an urban wastewater treatment plant, and investigates by statistical methods whether there is a relationship between micropollution and macropollution (TSS, COD, BOD, $\mathrm{TN}, \mathrm{TP})$ entering and leaving the studied wastewater treatment plant.

\section{Materials and Methods}

\subsection{WWTP Description and Sampling Points}

The Al-Hoceima wastewater treatment plant treats $9,600 \mathrm{~m}^{3}$ of wastewater per day (Supplementary material, Fig. S1). Pre-treatment (screening and grit removal) is the first stage of wastewater treatment. Then, an activated sludge unit with extended aeration (two streams, A and B, composed of a biological reactor combined with a secondary settling tank) ensures the removal of carbon and nitrogen. Activated sludge is one of the highest performance activated sludge unit configurations available, as it operates at very low loadings $\left(<0.32 \mathrm{~kg} \mathrm{BOD}_{5} /\left(\mathrm{m}^{3}\right.\right.$.d) $\left.[20]\right)$. Each stream comprises a biological reactor and a clarifier. Each biological reactor is divided into two parts: one for the aerobic zone which constitutes the core of the process in which the bacterial metabolism that causes the purification takes place, and the other for the anoxic zone (20\% of the reactor volume) installed immediately upstream of the tank. Finally, the effluent undergoes tertiary treatment by micro-screening and UV disinfection to complete the removal of particles and pathogens [21].

Our research focused on 46 micropollutants from different activities of our daily lives: 16 PAHs (Acenaphthene, Acenaphthylene, Anthracene, Benzo(a)anthracene, Benzo(a)pyrene, Benzo(b)fluoranthene, Benzo(g,h,i)pyrene, Benzo(k)fluoranthene, Chrysene, Dibenzo(a,h)anthracene, Fluoranthene, Fluorene, Indeno(1,2,3,cd) pyrene, Naphthalene, Phenanthrene and Pyrene), 18 PCBs (PCB-28, PCB-52, PCB-77, PCB-81, PCB-101, PCB-105, PCB-114, PCB-118, PCB-123, PCB-138, PCB-153, PCB-156, PCB-157, PCB-167, PCB-169, PCB-180 and PCB-189), and $12 \mathrm{HMs}$ (Cu, Zn, Fe, Mn, Cd, Pb, As, $\mathrm{Ni}, \mathrm{Ba}, \mathrm{Cr}$, Co and $\mathrm{Hg}$ ).

Four different sampling points, which correspond to raw wastewater (RW), pretreated wastewater (PW), treated wastewater (TW) and final wastewater (FW) (after tertiary treatment), were considered (Fig. 2). A total of three sampling campaigns were completed. Composite samples were taken at each site, $24 \mathrm{~h}$ a day, through refrigerated (at $4^{\circ} \mathrm{C}$ ) auto-samplers. To avoid problems related to sample contamination and/or pollutant adsorption during sampling, the samplers were equipped with glass bottles and Teflon® pipes. To prevent any modification of the pollutant distribution between dissolved and particulate phases, the samples were filtered as soon as possible on a $0.45-\mu \mathrm{m}$ filter to remove fine particulates. After filtration, the dissolved proportion was analyzed within $24 \mathrm{~h}$ of sampling, while the particulate proportion was analyzed within $48 \mathrm{~h}$. The concentrations of PAHs and PCBs in the collected samples were determined by Gas Chromatography-Mass Spectrometry (GC-MS) and for HMs by Inductively Coupled Plasma-Optical Emission Spectroscopy 


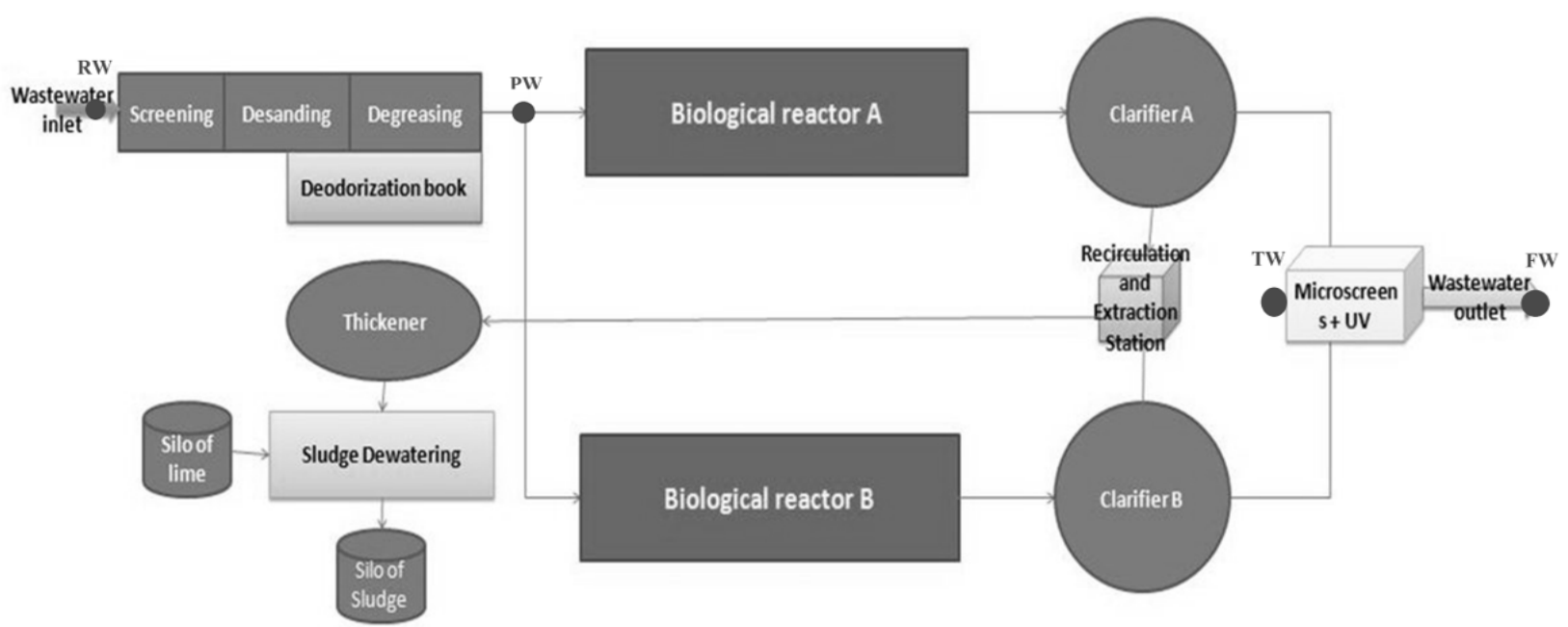

Fig. 2. The treatment process and sampling points in the WWTP.

Table 1. Conventional Wastewater Quality Parameters in RW and TW Effluents

\begin{tabular}{lcccc}
\hline Parameters & Unit & Raw wastewater & Treated wastewater & Removal Efficiency \% \\
\hline TSS & $\mathrm{mg} / \mathrm{L}$ & $353 \pm 52$ & $13.43 \pm 2.32$ & $96.15-99.00$ \\
COD & $\mathrm{mg} \mathrm{d} \mathrm{O} 2 / \mathrm{L}$ & $844.28 \pm 69.66$ & $36.92 \pm 5.36$ & $95.50-98.30$ \\
BOD & $\mathrm{mg} \mathrm{d} \mathrm{O} 2 / \mathrm{L}$ & $569.27 \pm 15.60$ & $10.09 \pm 1.54$ & $97.20-98.40$ \\
Total Nitrogen & $\mathrm{mg} / \mathrm{L}$ & $85.18 \pm 7.85$ & $4.77 \pm 0.54$ & $95.25-97.23$ \\
Total phosphorus & $\mathrm{mg} / \mathrm{L}$ & $8.94 \pm 0.35$ & $4.74 \pm 0.57$ & $46.80-51.17$ \\
\hline
\end{tabular}

(ICP-OES) (more information in Supplementary material).

\subsection{Conventional Wastewater Quality}

Table 1 shows the values of the wastewater quality parameters during the sampling campaigns. These include chemical oxygen demand (COD), biological oxygen demand (BOD), total suspended solids (TSS), total phosphorus (TP) and total nitrogen (TN). And their removal efficiency calculated between RW and FW (RE, in $\%$ ). A mean value + standard deviation of all campaigns are given for each parameter.

\subsection{Statistical Analysis}

Data analysis and statistics were performed using XLSTAT software (Addinsoft). First, a principal component evaluation was performed to visually show any correlation between micropollution and macropollution parameters. Correlations were calculated using the Pearson coefficient. Multiple Linear Regression (MLR) was then used to quantitatively determine the variables of interest.

\section{Results and Discussion}

\subsection{Occurrence of Micropollutants in Raw Wastewater}

As can be seen from the average removals (Table 1), the plant reaches a high removal of TSS, COD, BOD, and TN (> 90\%) and, to a lesser degree, $\mathrm{TN}$ ( $>40 \%$ ). The effluents at the end of the tertiary treatment have TSS 10-20 mg/L, BOD 10-15 mg/L, COD 30-40 mg/L, TN 5-10 mg/L, and TP 1-5 mg/L. However, effluent quality meets national and international standards for wastewater discharges.

In total, 33 of the 46 target molecules were detected in raw wastewater. All micropollutants identified in the wastewater samples and their distribution status at WWTP was presented in Table S1 (Supplementary material). Thirteen of the elements were detected only occasionally in raw water (only once over the three campaigns) and at concentration lev-els close to detection limits. These molecules, including eight PCBs, three heavy metals (As, $\mathrm{Cr}$, and Co), and two PAHs (Chrysene and Dibenzo(a,h)Anthracene). Fig. 3 shows the re-sults obtained for the 33 substances that have been quantified in raw wastewater with the total concentrations of each compound measured during the different campaigns. And detection limits are presented in Table S2 (Supplementary material). This allows us to appreciate the heterogeneous nature of the concentration levels of these 36 substances, with concentrations ranging from 0.02 to $850 \mu \mathrm{g} / \mathrm{L}$. This panel of molecules can, however, be divided schematically into three groups with very different concentration values.

Group 1 includes compounds with high concentration levels between 1 and $850 \mu \mathrm{g} / \mathrm{L}$. Logically, in this group we find the metallic elements (Fe [820-845 $\mu \mathrm{g} / \mathrm{L}], \mathrm{Zn}[365-390 \mu \mathrm{g} / \mathrm{L}], \mathrm{Cu}[288-298 \mu \mathrm{g} / \mathrm{L}]$, Mn [140-150 $\mu \mathrm{g} / \mathrm{L}]$, Ba [90-97 $\mu \mathrm{g} / \mathrm{L}], \mathrm{Pb}[28-35 \mu \mathrm{g} / \mathrm{L}]$, Ni [5-8 $\mu \mathrm{g} / \mathrm{L}]$, Cd [4.1-5 $\mu \mathrm{g} / \mathrm{L}], \mathrm{Zn}[1.2-1.5 \mu \mathrm{g} / \mathrm{L}])$. These substances are present 


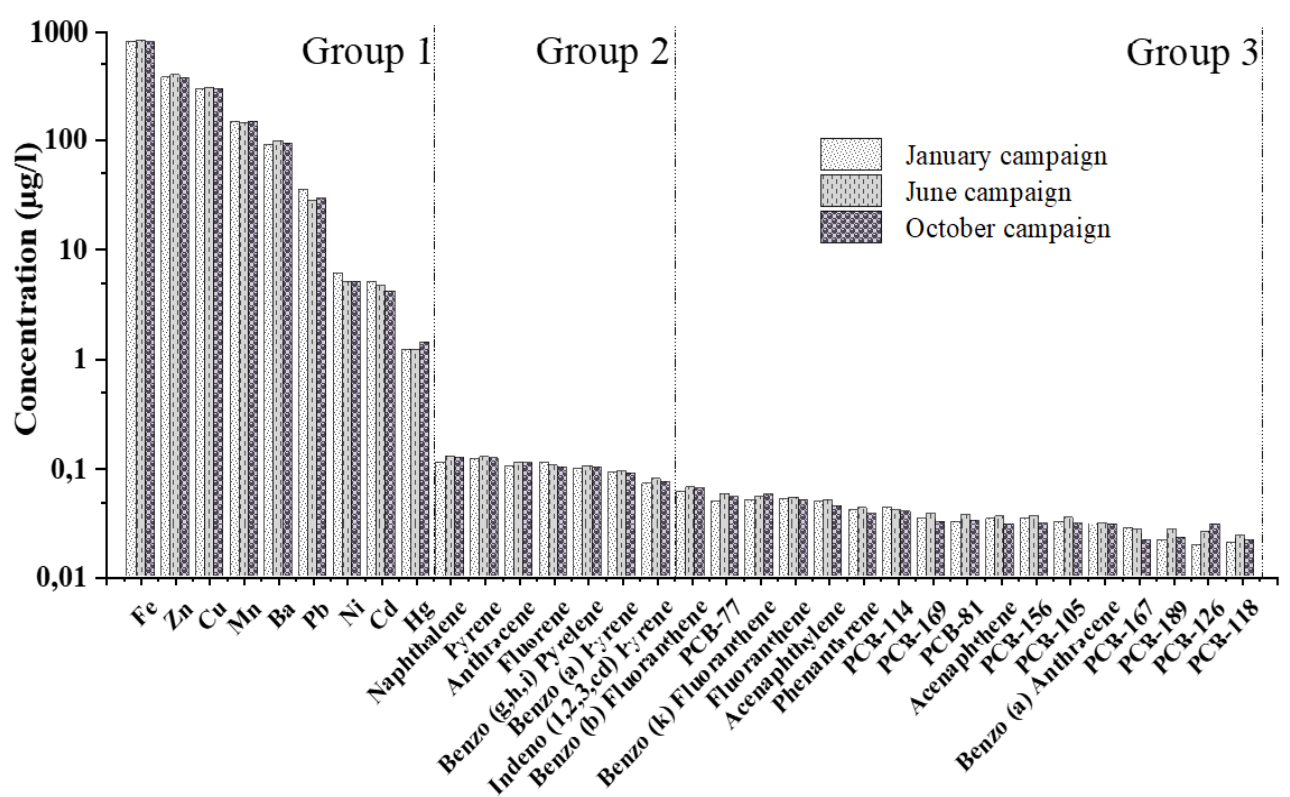

Fig. 3. Micropollutant concentrations in raw wastewater.

due to their intensive use in industry and household products. Currently, metals are used as chemical supplements in a wide variety of consumer products or are used in several metal finishing processes [22].

Group 2 includes substances present in raw sewage at concentration levels between 0.09 and $1 \mu \mathrm{g} / \mathrm{L}$. This group includes the main high molecular weight PAHs as well as low molecular weight PAHs (Naphthalene, Pyrene, Anthracene, Fluorene, Benzo(g,h,i) Pyrene, Benzo(a)Pyrene, Indeno(1,2,3,cd)Pyrene). Their presence in wastewater is probably related to automobile fuel combustion, domestic combustion (coal, wood, etc.), industrial production (steel mills, aluminum smelters, etc.), energy production (oil or coal-fired power plants, etc.) and incinerators. Such substances are often identified in wastewater, as already noted by [23] for Norway case or by [24] for Paris case.

Group 3 includes substances present in raw water at concentration levels between 0.01 and $0.09 \mu \mathrm{g} / \mathrm{L}$. This group includes PCBs (PCB-77, PCB-114, PCB-169, PCB-81, PCB-156, PCB-105, PCB-167, PCB-189, PCB-126, PCB-118). In addition to these PCBs, some PAHs (Benzo(b)Fluoranthene, Benzo(k)Fluoranthene, Fluoranthene, Acenaphthylene, Phenanthrene, Acenaphthene, Benzo(a)Anthracene) are also present in this group.

\subsection{Fate and Removal of Micropollutants in WWTP}

Analyses of micropollutants in wastewater samples taken at different stages of treatment showed that PAHs, PCBs, and HMs were widely present in the wastewater treatment plant. The results of the quantification of target MPs are presented in Fig. 4. In general, the Al-Hoceima City wastewater treatment plant removes micropollutants. By comparing MPs levels, it was easy to see that the levels of HMs were higher than those of PAHs and PCBs in the treatment stages. According to the results obtained, four categories have been defined, compounds for which discounts are less than $20 \%$ (poorly eliminated), between 20 and 50\% (eliminated weekly), between 50 and $80 \%$ (moderately eliminated) and more than $80 \%$ (effectively eliminated) (Fig. 5).

Following the criteria defined above, the metals are generally well retained, with percentages ranging from 50 to $80 \%$ for $\mathrm{Cu}$, $\mathrm{Mn}, \mathrm{Pb}, \mathrm{Cd}, \mathrm{Ni}$ and $\mathrm{Ba}$ (moderately removed) and above $80 \%$ for $\mathrm{Zn}, \mathrm{Fe}$ and $\mathrm{Hg}$ (effectively removed). Total metal concentrations decreased significantly between RW and FW, confirming that metal removal is likely to be strongly correlated with a metal affinity for particulate matter.

Depending on the physicochemical properties of the pollutant, the abatements observed for organic compounds are very different from one molecule to another. Some molecules, belonging to PCBs, are poorly eliminated $(<20 \%)$, while high molecular weight PAHs (4-6 cycles, HMW PAHs) are moderately eliminated (50\% to $80 \%$ ). These differences in behavior can be explained by considering the physicochemical properties of the dosed molecules and, in particular, the hydrophobicity of a molecule is generally assessed based on the octanol-water partition coefficient (Kow). Hydrophobic molecules, which are strongly associated with organic particles, are removed efficiently, while hydrophilic molecules, which are essentially transported in the dissolved phase, are removed weekly during the treatment steps.

Pretreatment has no significant impact on PAHs, PCBs, and HMs concentrations. The secondary treatments used are carbon removal, nitrification, and then denitrification. These techniques are initially designed to reduce carbon and nitrogen concentrations in wastewater. But they also remove micropollutants. Indeed, this work has shown that PAH and PCB abatements are obtained during biological treatment and that the phenomena are mainly observed during the secondary carbon treatment and nitrification phases.

Tertiary processes (microfiltration and UV disinfection) have 


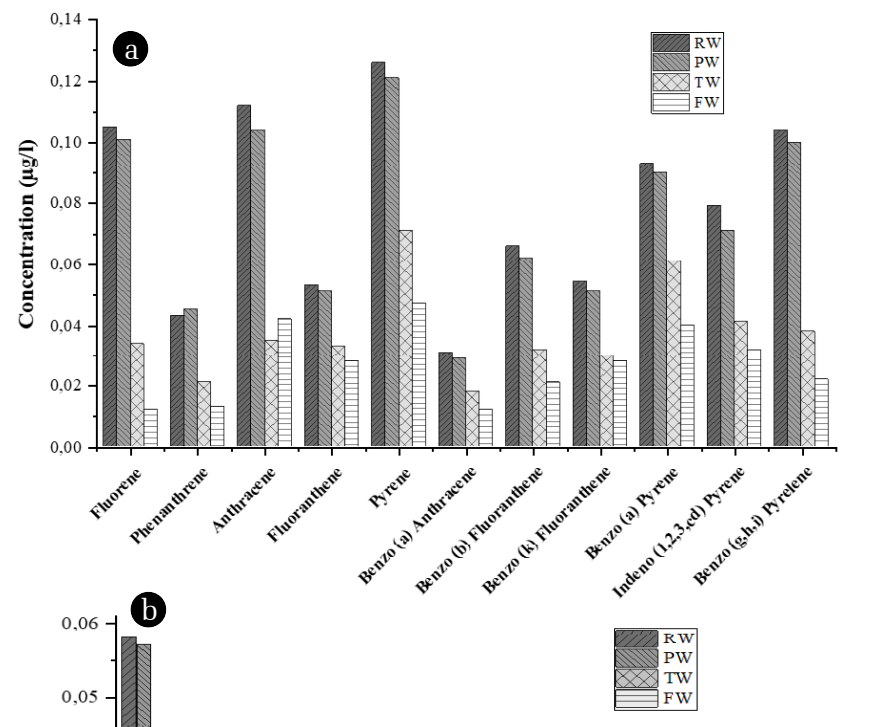

at the inlet and outlet of the treatment plant belonging to groups 1 and 2 (Fig. 3). An examination by Principal Component Analysis (PCA) showed linear relationships between micropollution and macropollution entered the WWTP and was also found when considering the input and output concentrations of micropollutants and macropollutants.

After observing the correlations between micropollution and macropollution on correlation circles, an MLR method was then used for the quantitative description of a variable of interest. Initially, we tried to identify the pollution that enters the treatment plant, attempting to establish relationships between micropollution and macropollution. Then, we have looked for the connection that exists between inlet and outlet micro-pollution and outlet macro-pollution. In the end, the validity of the description of the micropollution at the outlet was also investigated concerning the macropollution at the inlet and outlet commonly measured at the treatment plant.

\subsubsection{Micropollutants and macropollutants inlet relationship}

MLR was applied to examine whether there are any specific relationships between micropollutants inlet concentrations and five commonly measured macropollutant inlet variables concentrations (TSS, COD, BOD, TN, and TP).

$$
\mathrm{C}_{\text {micro }_{\text {in }}}{ }^{\text {cal }}=\mathrm{n} \cdot\left(\mathrm{C} \text { macro }_{\text {in }}{ }^{\mathrm{M}}\right)
$$

In which $\mathrm{C}$ micro $_{\text {in }}{ }^{\text {cal }}$ is the calculated concentration at the inlet of a micropollutant, and $\mathrm{C}$ macro ${ }_{\text {in }}{ }^{\mathrm{M}}$ is the macropollution measured at the inlet of the treatment plant.

Because of the complicated nature of the system, only simple types of regression were considered: linear, square, logarithmic, and inverse functions. The regression coefficient (r) between the measured micropollutants concentrations and the values given by its regression model made it possible to estimate the precision of the numerical expressions to describe the parameters (the intensity of the relationships). The implementation of conversions did not significantly increase the degree of correlation. Therefore, Table 2 presents only the coefficients of the linear expressions. For example, the concentration of $\mathrm{Fe}$ at the inlet may be expressed as:

$$
\begin{gathered}
\text { Fe in }=829.696-20.571 \times \mathrm{TSS} \text { in }-0.004 \times \mathrm{COD} \text { in } \\
+0.064 \times \mathrm{BOD} \text { in }-0.061 \times \mathrm{TN} \text { in }-0.601 \times \mathrm{TP} \text { in }
\end{gathered}
$$

All expressions obtained satisfactory reliability: the trend of the calculated values was the same as that of the measured values within the $96 \%$ reliability interval.

We have determined the concentrations of heavy metals essentially by a constant (first column of Table 3) because these compounds enter the WWTP in almost constant concentrations. So they appear to have poor relationships with the measured macropollution parameters (varying) throughout the day.

\subsubsection{Micropollutants at the outlet relationship with the micro- pollutants at the inlet and the macropollution at the outlet} Secondly, it was investigated whether an overall performance of the sewage treatment plant (removal of macropollution) affected 


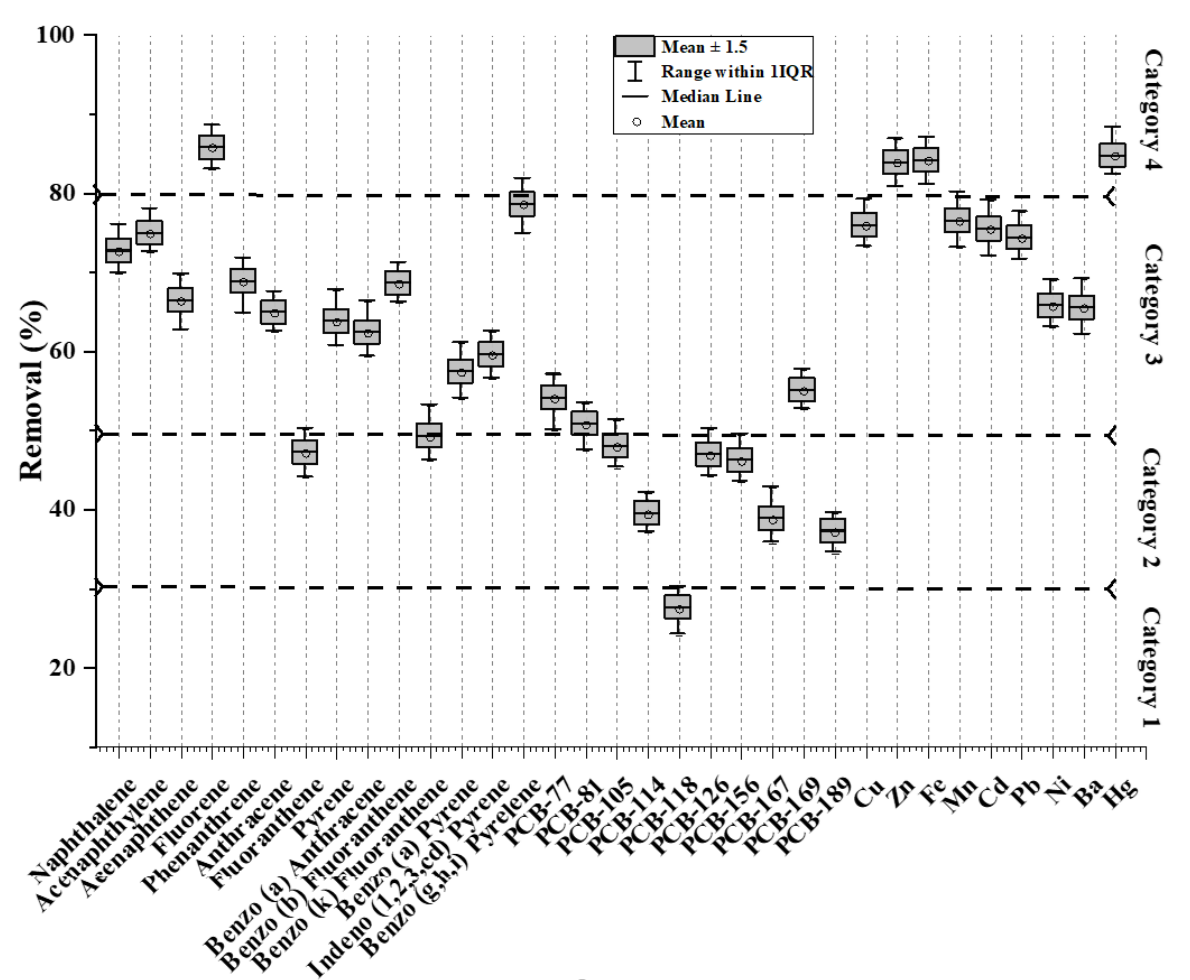

Fig. 5. Removal efficiency of micropollutants from WWTP.

Table 2. Linear Regression Structures Describing Inlet Micropollutants Concentrations in Relation to Macropollution Measured at the WWTP inlet, and Model Coefficients ( $r$ )

\begin{tabular}{|c|c|c|c|c|c|c|c|}
\hline & Constant & TSS in & COD in & BOD in & TN in & TP in & $\mathbf{r}$ \\
\hline $\mathrm{Fe}$ in & 829.696 & $-20,571$ & -0.004 & 0.064 & -0.061 & -0.601 & 0.351 \\
\hline $\mathrm{Zn}$ in & 421.252 & -25.975 & 0.002 & -0.053 & -0.087 & 1.128 & 0.456 \\
\hline $\mathrm{Cu}$ in & 303.728 & -8.112 & -0.001 & 0.044 & -0.005 & -3.336 & 0.327 \\
\hline Mn in & 133.555 & 6.823 & 0.004 & 0.014 & 0.107 & -1.507 & 0.168 \\
\hline $\mathrm{Ba}$ in & 131.942 & 25.480 & -0.018 & -0.090 & 0.013 & 2.242 & 0.562 \\
\hline $\mathrm{Pb}$ in & 80.791 & 4.025 & 0.010 & -0.068 & -0.213 & -0.659 & 0.419 \\
\hline $\mathrm{Ni}$ in & 19.959 & 0.048 & 0.006 & -0.020 & -0.048 & -0.312 & 0.190 \\
\hline $\mathrm{Cd}$ in & 12.325 & 0.662 & 0.001 & -0.009 & -0.010 & -0.191 & 0.673 \\
\hline $\mathrm{Hg}$ in & -4.208 & -1.219 & 0.001 & 0.008 & 0.011 & -0.036 & 0.743 \\
\hline Naphthalene in & 0.09958 & 0.02783 & -0.00001 & -0.00002 & -0.00025 & 0.00669 & 0.897 \\
\hline Pyrene in & 0.14120 & 0.00069 & 0.00001 & -0.00002 & -0.00006 & -0.00004 & 0.498 \\
\hline Anthracene in & 0.19910 & -0.00159 & 0.00001 & -0.00006 & -0.00010 & -0.00437 & 0.912 \\
\hline Fluorene in & 0.16832 & 0.01980 & -0.00004 & -0.00007 & 0.00002 & -0.00037 & 0.903 \\
\hline Benzo (g,h,i) Pyrelene in & 0.08700 & -0.01772 & 0.00001 & 0.00004 & 0.00019 & -0.00224 & 0.447 \\
\hline Benzo (a) Pyrene in & 0.11531 & -0.01722 & 0.00002 & -0.00001 & -0.00007 & -0.00209 & 0.715 \\
\hline Indeno $(1,2,3, \mathrm{~cd})$ Pyrene in & 0.02694 & 0.02311 & -0.00001 & 0.00005 & 0.00012 & 0.00142 & 0.468 \\
\hline
\end{tabular}

the efficiency of the removal of micropollution. The MLR was therefore used to investigate whether there are relationships between the outlet micropollutant concentrations and its inlet concentrations and the macropollution concentrations measured at the outlet:
$\mathrm{C}$ micro $_{\text {out }}{ }^{\text {cal }}=\mathrm{n} \hat{\mathrm{I}}\left(\mathrm{C}\right.$ micro $_{\text {in }}{ }^{\mathrm{M}} \cdot \mathrm{C}$ macro $\left._{\text {out }}{ }^{\mathrm{M}}\right)$

In which $\mathrm{C}$ micro $_{\text {out }}{ }^{\text {cal }}$ is the calculated concentration at the outlet of a micropollutant, $\mathrm{C}$ micro $_{\text {in }}{ }^{\mathrm{M}}$ is the measured concentration 
Table 3. Linear Regression Structures Showing the Outlet Micropollutant Concentrations in Relation to the Macropollution Measured at the Outlet of the WWTP and the Micropollutant Measured at the Inlet

\begin{tabular}{lcccccccc}
\hline & Constant & Micro in & TSS out & COD out & BOD out & TN out & TP out & r \\
\hline Fe out & 567.425 & -0.515 & 401.219 & 0.223 & -0.097 & 1.550 & -1.625 & 0.877 \\
Zn out & 70.151 & 0.001 & -398.796 & 0.096 & -0.659 & -0.091 & 0.636 & 0.144 \\
Cu out & -39.961 & 0.390 & 248.438 & 0.027 & 0.824 & -2.673 & -0.276 & 0.615 \\
Mn out & 33.089 & -0.050 & -55.317 & 0.041 & 0.082 & 0.492 & 0.804 & 0.052 \\
Ba out & 0.519 & -4.413 & 502.742 & -0.518 & 0.135 & 1.488 & -1.472 & 0.753 \\
Pb out & 25.433 & -0.110 & -169.684 & -0.118 & -0.350 & -0.916 & 0.158 & 0.402 \\
Ni out & -7.011 & -0.064 & 166.052 & -0.036 & 0.299 & 0.708 & 0.699 & 0.476 \\
Cd out & -0.924 & -0.115 & 17.800 & 0.020 & 0.024 & 0.302 & 0.010 & 0.720 \\
Hg out & 0.506 & -0.226 & 33.957 & -0.013 & 0.037 & -0.072 & 0.014 & 0.477 \\
Naphthalene out & 0.03887 & 0.05349 & -1.27935 & 0.00016 & -0.00171 & 0.00063 & 0.00341 & 0.678 \\
Pyrene out & -0.37774 & 3.02611 & -0.65862 & 0.00070 & -0.00101 & 0.00875 & -0.00103 & 0.736 \\
Anthracene out & 0.10767 & -0.52574 & 0.39575 & -0.00010 & 0.00010 & 0.00001 & -0.00188 & 0.748 \\
Fluorene out & -0.03906 & 0.49325 & 0.88204 & -0.00017 & 0.00175 & -0.00180 & -0.00299 & 0.909 \\
Benzo (g,h,i) Pyrelene out & 0.09045 & -0.81902 & -0.18452 & 0.00010 & 0.00086 & 0.00064 & 0.00096 & 0.790 \\
Benzo (a) Pyrene out & 0.05155 & -0.39066 & -0.69645 & 0.00051 & -0.00107 & 0.00518 & 0.00078 & 0.930 \\
Indeno (1,2,3,cd) Pyrene out & -0.00123 & 0.07406 & -0.38139 & 0.00002 & 0.00016 & 0.00214 & 0.00456 & 0.679 \\
\hline
\end{tabular}

at the intlet of a micropollutant and $\mathrm{C}$ macro $_{\text {out }}{ }^{\mathrm{M}}$ is the macropollution measured at the outlet of the treatment plant.

The coefficients of the linear numerical expressions between the measured micropollutant concentrations and the values given by its regression model are shown in Table 3. The reliability (r) was satisfactory for all expressions, except $\mathrm{Zn}, \mathrm{Mn}$ and $\mathrm{Pb}$, Which are within the $96 \%$ confidence interval. Small regression coefficients indicate weak relationships between these molecule concentrations and the macro- and micro-pollution parameters used.

3.3.3. Micropollutants at the outlet relationship with the macropollution measured at the inlet and the outlet

As a final step, we tried to find out whether it was feasible to obtain an estimate of the micropollution released into water bodies simply by measuring inlet and outlet macropollution concentrations (measured daily at a wastewater treatment plant).

The relations between micropollution and macropollution at the inlet of the wastewater treatment plant have been successfully established by equation (1). Concentrations of micropollution at the output were described by the equation (3). When the equations (1) and (3) are combined, the concentrations of outlet micropollutants can be related to the macropollution inlet and outlet of the WWTP is:

$$
\mathrm{C} \text { micro }_{\text {out }}{ }^{\text {est }}=\mathrm{n} \hat{\mathrm{I}}\left(\mathrm{C} \text { macro }_{\text {in }}{ }^{\mathrm{M}} \cdot \mathrm{C} \text { macro }_{\text {out }}{ }^{\mathrm{M}}\right)
$$

Linear numerical expressions are given in Table S3 (Supplementary material). Table S4 shows the calculated micropollutant concentrations at the outlet of the treatment plant. All expressions on the measurements were reliable: the micropollutant concentrations calculated follow the same trend as the measured values (high regression coefficient, r).

Using this statistical analysis, it was possible to find correlations between the concentrations of micropollutants at the outlet and the macropollution parameters at the inlet and outlet. Of course, the model needs to be validated by further sampling campaigns. This approach, however, could be an operational method for estimating the outlet concentrations of micropollutants discharged to the receiver body by measuring only the macropollution parameters.

Operators or researchers of WWTPs are often searching for ways to estimate parameters without measuring them. It is even more significant for micropollutants, which are difficult to analyze and therefore need specific equipment and skills. All WWTPs operate with specific technology and samples. Consequently, to develop models for a given WWTP, it is essential to make some preliminary measurements in the WWTP. The estimation is possible under two conditions: that the operating regime is stationary (as in our measurements) and that there is no change in the behavior of the population in the urban area discharging wastewater. Further correlations will have to be searched if the WWTP undergoes technological changes or changes in human behavior.

\section{Conclusions}

This study investigated the occurrence of organic and inorganic micropollutants resulting from human activity in raw wastewater, as well as their fate and behavior in a wastewater treatment plant.

This work first confirmed that a wide range of micropollutants is present in raw sewage. Out of the 46 molecules studied, 33 substances were identified. In general, heavy metal concentrations varied from 1 to $850 \mu \mathrm{g} / \mathrm{L}$, whereas other organic micropollutants were in the range of 0.01 to $1 \mu \mathrm{g} / \mathrm{L}$. The majority of these molecules are present as a result of their intense use in a wide variety of household appliances and consumer products. 
The wastewater treatment plant studied was successful in eliminating most micropollutants, so the quality of the effluent released was following national and international wastewater discharges standards. Despite the presence of trace residual MPs in the effluent released, they would not result in any pollution of the aquatic environment due to dilution factors.

In addition to providing information on the fate of micropollutants in the WWTP process, the statistical analysis (MLR) has mathematically characterized the actual observed (or unobserved) elimination of micropollutants. Through statistical evaluation of the data, it was possible to establish a diagnosis of the operation of the treatment plant by relating the micropollutants at the inlet and outlet of the plant to the macropollution parameters at the outlet. Even if we did not have sufficient measurements to confirm the model on a new set of measurements, it might be a potential tool to describe any WWTP and to estimate the micropollution discharged from it without having to measure it.

\section{Acknowledgments}

We would like to thank the staff of the Al-Hoceima city wastewater treatment plant for their assistance during this work.

\section{Author contributions}

Y.E.H. (Ph.D. student) conducted all the experiments and wrote the manuscript. F.D. (Professor) wrote and revised the manuscript.

\section{References}

1. Gallé T, Köhler C, Plattes M, et al. Large-scale determination of micropollutant elimination from municipal wastewater by passive sampling gives new insights in governing parameters and degradation patterns. Water Res. 2019;160:380-393.

2. Margot J, Kienle C, Magnet A, et al. Treatment of micropollutants in municipal wastewater: ozone or powdered activated carbon? Sci. Total Environ. 2013;461:480-498.

3. Deblonde T, Cossu-Leguille C, Hartemann P. Emerging pollutants in wastewater: a review of the literature. Int. J. Hyg. Environ. Health 2011;214(6):442-448.

4. Ma XY, Dong K, Tang L, et al. Investigation and assessment of micropollutants and associated biological effects in wastewater treatment processes. J. Environ. Sci. 2020;94:119-127.

5. Vo HNP, Koottatep T, Chapagain SK, et al. Removal and monitoring acetaminophen-contaminated hospital wastewater by vertical flow constructed wetland and peroxidase enzymes. $J$. Environ. Manage. 2019;250:109526.

6. Bolong N, Ismail A, Salim MR, Matsuura TA. Review of the effects of emerging contaminants in wastewater and options for their removal. Desalination 2009;239(1-3):229-246.

7. Daughton CG. Ternes TA. Pharmaceuticals and personal care products in the environment: agents of subtle change? Environ. Health Perspect. 1999;107(suppl 6):907-938.

8. Gurung K, Ncibi MC, Sillanpää M. Removal and fate of emerging organic micropollutants (EOMs) in municipal wastewater by a pilot-scale membrane bioreactor (MBR) treatment under varying solid retention times. Sci. Total Environ., 2019;667:671-680.

9. Rogowska J, Cieszynska-Semenowicz M, Ratajczyk W, Wolska L. Micropollutants in treated wastewater. Ambio 2019:1-17.

10. Katsoyiannis A, Samara C. Persistent organic pollutants (POPs) in the sewage treatment plant of Thessaloniki, northern Greece: occurrence and removal. Water Res. 2004;38(11):2685-2698.

11. Pasquini L, Munoz J-F, Rimlinger N, et al. Assessment of the fate of some household micropollutants in urban wastewater treatment plant. Chemical Papers 2013;67(6):601-612.

12. Blanchard M, Teil M-J, Ollivon D, et al. Origin and distribution of polyaromatic hydrocarbons and polychlorobiphenyls in urban effluents to wastewater treatment plants of the Paris area (France). Water Res. 2001;35(15):3679-3687.

13. Balcioğlu EB, Gönülal O, Güreşen SO, Aksu A, Öztürk B. Comparison and origins of polycyclic aromatic hydrocarbons (PAHs) in the entrance and the exit of the Turkish Straits System (TSS). Mar. Pollut. Bull. 2018;136:33-37.

14. Blanchard M, Teil M, Ollivon D, Legenti L, Chevreuil M. Polycyclic aromatic hydrocarbons and polychlorobiphenyls in wastewaters and sewage sludges from the Paris area (France). Environ. Res. 2004;95(2):184-197.

15. Chipasa KB. Accumulation and fate of selected heavy metals in a biological wastewater treatment system. Waste Manage. 2003;23(2):135-143.

16. Kiss AN, Marx B, Mourot G, Schutz G, Ragot J. Observers design for uncertain Takagi-Sugeno systems with unmeasurable premise variables and unknown inputs. Application to a wastewater treatment plant. J. Process Control. 2011;21(7):1105-1114.

17. Avella A, Görner T, Yvon J, et al. A combined approach for a better understanding of wastewater treatment plants operation: Statistical analysis of monitoring database and sludge physico-chemical characterization. Water Res. 2011;45(3):981-992.

18. HCP Rabat. Les Indicateurs Sociaux du Maroc [Internet]. Morocco: HCP Rabat; c2014. Available from: https:/www. hcp.ma/downloads/Indicateurs-sociaux_t11880.html

19. Dimane F, Haboubi K, Hanafi I, El Himri A, Aridaloussi K. Impact des facteurs de pollution sur la qualité des eaux de la zone aval de la vallée de l'oued Nekor (Al-Hoceima, Maroc). Eur. Sci. J. 2017;13(3):44-60.

20. Gaïd A. Traitement des eaux résiduaires. Techniques de l'Ingénieur C. 2008;5:220.

21. Dimane F, Haboubi K, Hanafi I, El Himri A. Étude de la Performance du Dispositif de Traitement des Eaux UsÉes par Boues ActivÉes de la ville d'Al-Hoceima, Maroc. Eur. Sci. J. 2016;12(17):272.

22. Rule K, Comber S, Ross D, et al. Diffuse sources of heavy metals entering an urban wastewater catchment. Chemosphere 2006;63(1):64-72.

23. Vogelsang C, Grung M, Jantsch TG, Tollefsen KE, Liltved H. Occurrence and removal of selected organic micropollutants at mechanical, chemical and advanced wastewater treatment plants in Norway. Water Res. 2006;40(19):3559-3570.

24. Gasperi J, Garnaud S, Rocher V, Moilleron R. Priority pollutants in wastewater and combined sewer overflow. Sci. Total Environ. 2008;407(1):263-272. 